\title{
Case Report: The Psychosocial Consequences of Natural Disasters: A Case Study
}

\author{
Masoumeh Kamaledini $^{*}$ (D), Mostafa Azkia ${ }^{2}$ (D) \\ 1. Lecturer faculty Red Crescent Institute, University of Applied Sciences and Technology, Tehran, Iran. \\ 2. Department of Social Sciences, Faculty of Social and Behavioral Sciences, University of Tehran, Iran.
}

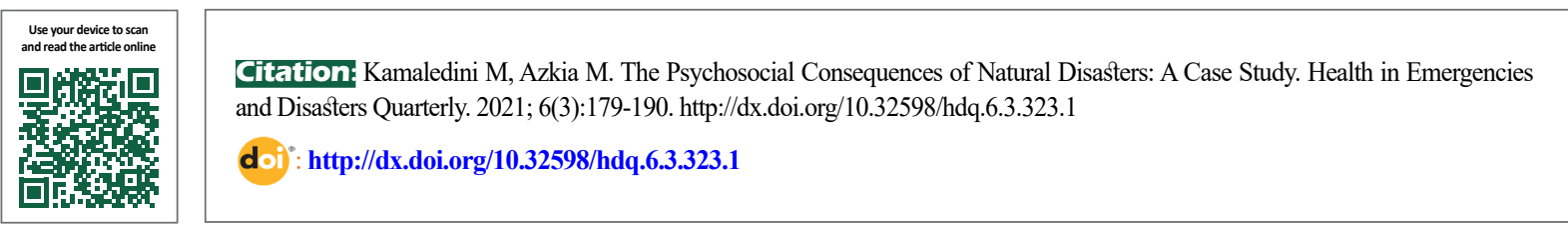

\section{(1) (\$)}

Article info:

Received: 10 Dec 2020

Accepted: 15 Feb 2021

Available Online: 01 Apr 2021

\section{Keywords:}

Natural disaster, Gender, Psychosocial consequences

\section{ABSTRACT}

Background: Earthquake is one of the most important and destructive natural hazards in Iranian cities, and the psychological and social consequences of catastrophe vary according to age, gender, economic and social class.

Materials and Methods: The present study is qualitative research that we conducted with the method of grounded theory research and to understand the social consequences of earthquakes in the social group of women living in Bam in 2017. We collected data, interpreted the extracted concepts, and analyzed the discovered social consequences using in-depth interview techniques and purposeful and theoretical sampling in Bam women's community.

Results: After interviewing five experts and 27 women, we reached the data saturation in 2 groups of the middle and lower economic class of Bam city and performed three coding steps for each narrative. According to the research findings, one of the direct and indirect consequences of the Bam earthquake disaster in women has been psycho-social trauma.

Conclusion: Earthquake, death of parents and close family members with Interventional conditions such as economic and cultural status, level of education of the individual and family have affected the experience of psycho-social trauma in women. Also, women who based on pre-crisis and pre-disaster chose irrational and passive strategies experienced more negative consequences than women who chose rational and active coping strategies. Finally, the theoretical inference is that there is a direct relationship between the intervening social context and the psychological and social harms caused by the disaster in women, which in addition to the functional relationship is also effective in aggravating the consequences of this impact.

\footnotetext{
* Corresponding Author:

Masoumeh Kamaledini, PhD.

Address: Lecturer faculty Red Crescent Institute, University of Applied Sciences and Technology, Tehran, Iran.

E-mail: mkamalledini@gmail.com
} 


\section{Introduction}

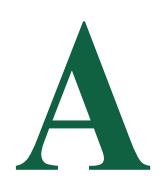

6.7 magnitude earthquake on December 26, 2003, in less than 30 seconds, destroyed a large part of Bam City, Iran, leading to a high death rate. The city was socioeconomically disintegrated. Besides, the resulting psychological trauma has long plagued the residents of Bam City. Natural disasters, such as earthquakes, floods, and droughts can be disastrous; they cause widespread destruction, lead to the death of hundreds of individuals, and leave survivors in need of domestic and international assistance. When natural disasters challenge the social order, the natural way of life, the values, and beliefs, a disaster is created; however, disasters present various consequences among survivors, concerning their age, gender, and socioeconomic class.

According to the estimated gender ratio of the population of Bam and Barvat cities, at the time of the earthquake, the male population was $2.86 \%$ higher than the female population. Furthermore, the female mortality rate was higher than the male in catastrophes. Children, females, and individuals with disabilities encountered further complications; e.g., "in the wake of the earthquake of Maharashtra City in India, the high death rate of women was due to their presence at home while the men were busy outside that moment" [1].

The disaster affects both genders' biopsychological health; however, women are among the most vulnerable groups experiencing greater harm than men. Females are further affected than men by the disorganization and abnormality of the psychosocial rules destroyed in the disasters. Being a woman, along with factors, such as social class+gender (poor women)+age+social class + gender (poor older women)+age+social class, ethnicity+gender(poor elderly minority women), will make them the most vulnerable group in disasters [2]. Society loses its socio-political order and social structures collapse in natural disasters, leading to widespread catastrophes. Ignoring certain social groups is manifested in the form of short-term and long-term psychosocial and economic consequences. Furthermore, the physical environment after the earthquake (ruined and out of sight spaces) may facilitate violence as well as physical and sexual harassment against females.

The physical varieties, different roles in the family and society, various societal expectations, multiple opportunities proved by the society for men and women, different biopsychological conditions, various experiences, and skills, etc. present females in different situations than males in natural disasters. Gender inequalities lead to more natural disasters among women in most countries, compared to men.
Gender-Wise inequalities further affect women in natural disasters in most countries [3].

Although 17 years have passed since the Bam earthquake, it is essential to address the issue of psychosocial health of Bam survivors. In general, the passing of time may reduce the severity of the psychological effects of disasters; however, the presence of these consequences in the social life of survivors is highly tangible. For example, Titchener and Kup (1976), after the Buffalo River flood disaster, observed family interactions and performed individual interviews. Accordingly, they found that $80 \%$ of survivors experienced nervous reactions, such as unresolved grief, shame, anger, and frustration. These clinical manifestations continued for two years after the flood [4]. Consequently, these symptoms, on whole, were called Buffalo Syndrome, i.e., widespread among the residents for numerous years.

A study by Livano et al. (2004) 4 years after the 1999 Greek earthquake found that from 157 individuals; 22\% and $15 \%$ reported depression and other disorders. Moreover, some of them were due to the intensity of fear during the earthquake and anxiety during the rescue operation [5]. Numerous years later, a study outlined a link between depression, previous mental health problems, and increased suicidal behaviors after natural disasters [6]. Statistics and interviews conducted in Bam City (during the earthquake and currently) have also emphasized the existence of the psychosocial consequences of the disaster. Furthermore, these psychological traumas have affected the socioeconomic contexts of Bam residents' lives. Therefore, combining psychosocial studies is necessary to provide preventive and interventional psychosocial measures in affected areas.

Recognizing female-wise social consequences of the Bam earthquake disaster is possible by documenting the lives of Bam-resident women, answering questions, and deeply understanding the social differences of the earthquake's impact on them. The following parts consider the narrative as the history of the present and express our perception of past phenomena. The narrators expressed their experiences concerning a historical event, like an earthquake through various narrations. Therefore, this research aimed to identify how our knowledge about earthquake disasters is formed through narratives.

Another purpose of this study was to increase knowledge about women and disasters. This goal was achieved through women's narratives of their experiences and those of others. This is because, despite the recurrence of disasters in the world, theoretical research respecting disaster is limited. Another aim of this study was to increase specialized knowledge concerning gender and disaster in Iran. 
Globally, at the beginning of the formation of the sociology of disaster and the gender crisis, this issue was among the few phenomena that attracted the attention of researchers. Moreover, this issue has been discussed in the sociology of disaster since 1980. However, there remains a gap in this area. Thus, gender and disaster researchers outlined the lack of data on gender patterns in crisis decision-making as well as women's voices in crisis discourse [7]. The detailed objectives of this study included the following:

- Recognizing the short-term and long-term social consequences of the Bam City earthquake in women's lives;

- Recognizing practical and effective solutions to reduce the social damage of earthquakes in women's lives;

- Considering the experiences and narrations of women survivors to discover, interpret, and understand the social consequences of the earthquake.

Achieving these goals enables us to consider various feminine perspectives and experiences in detail; therefore, examining the nature of women's lives in disasters is an opportunity to learn to build daily lives in times of crisis and normalcy among the affected women.

As per Corbin and Strauss (1991), in a qualitative study, the question identifies the subject of the study. It also provides the reader with the particular subject of interest to the researcher that designs two categories of questions [8]. We designed two categories of questions; general and partial or practical ones, general questions based on the research literature, such as the following:

- What general effects did the earthquake have on the personal and social lives of women in Bam City?

- How did the women in Bam City cope with the potential adverse consequences of the disaster?

- What were the emotional and psychosocial experiences of women in Bam City during the disaster?

Partial or practical questions were based on the data obtained from the initial interviews. Moreover, new questions were designed following the study participants' statements; eventually, this process has led to presenting non-repetitive data and the lack of production of more and non-repetitive data. For example, according to Ernreich (2003), individuals encounter unpleasant emotions and experiences after disasters. Besides, these reactions are a combination of confusion, fear, despair, helplessness, insomnia, physical pain, anxiety, anger, grief, shock, violence, mistrust, guilt, and the loss of self-confidence [9]. In this study, women participated in answering the following question: "how did you feel during the earthquake or in the following days?" They referred to extreme sadness, guilt, anger, despair, depression, and expecting death for the future. Answering these questions was among the main primary sources for extracting the initial concepts and categories; these were later the focus of the research to the below questions:

- What factors have been influential in the formation of psychosocial harm to women in Bam City?

- What have been the preferred strategies of young women to cope with this phenomenon?

-What are the consequences of this phenomenon in the personal and social life of women?

Disaster causes all survivors, regardless of gender, to experience stress. When a part of society is damaged, it is very painful, just as if a part of a human body is hurt; thus, the other parts of it are disrupted. As long as the topics of psychology and sociology were not addressed as important, geographical and physical injuries were considered a catastrophe. However, later, according to the results of field research, psychosocial trauma was also considered.

After the disaster, individuals experience unpleasant emotions. These reactions, according to Ernreich (2003), are a combination of confusion, fear, despair, insomnia, physical pain, anxiety, grief, shock, violence, mistrust, guilt, and the loss of self-confidence. However, during the disaster, the focus is mainly on physical damage and destroyed structures in urban and rural areas; accordingly, support systems paid less attention to humans.

Men and women play the prominent roles of a family as a wife or mother, daughter or sister, father or husband, son or brother, and child; thus, the family also changes with the disappearance of their role. Natural and human disasters, such as floods, earthquakes, and wars, in a short time, complicate the scroll of life and afflict a part of society by homelessness and the resulting displacement. These events present multiple materials, including economical, spiritual, and psychosocial effects on individuals [10]. Respecting the psychosocial harms of survivors, women are addressed as a vulnerable group. The main focus of families is significant in this regard. It is essential to assess their health status and provide them psychosocial support systems. Therefore, such research will increase the awareness and sensitivity of crisis management teams. 


\section{Materials and Methods}

There exist differences in semantic understanding in disaster studies. Besides, the available data highlighted the differences between humans and other natural phenomena. Accordingly, it is essential to assess individuals using various research methods. The relevant findings could help to interpret their behavior. These data are also beneficial in understanding the nature of the experience of individuals or phenomena about which data are scarce. Accordingly, in-depth interviews could be performed on disasters. Considering the research questions and exploring the social consequences of the disaster, the qualitative method was identified as the most appropriate research technique; finally, the grounded theory research method was used. This is because access to straightforward narratives and first-hand experiences of social groups after disasters by collecting da- tabases in qualitative methods will help the researcher focus on context research and exploration to confirm the collected information.

The current study investigated 27 young women living in Bam City, Iran, who survived the 2003 earthquake. The study subjects were selected by the purposive sampling method. All explored subjects were examined using 40-60-minute in-depth interviews. Initially, several women who had lived in tents, barracks, and camps in Bam City for at least a year after the earthquake were selected and interviewed. Next, other women were introduced or selected accordingly by theoretical sampling technique. We explored the effects of economic class and demographic characteristics on women's experiences. The next group was separated based on a residential area, educational level, and oc-

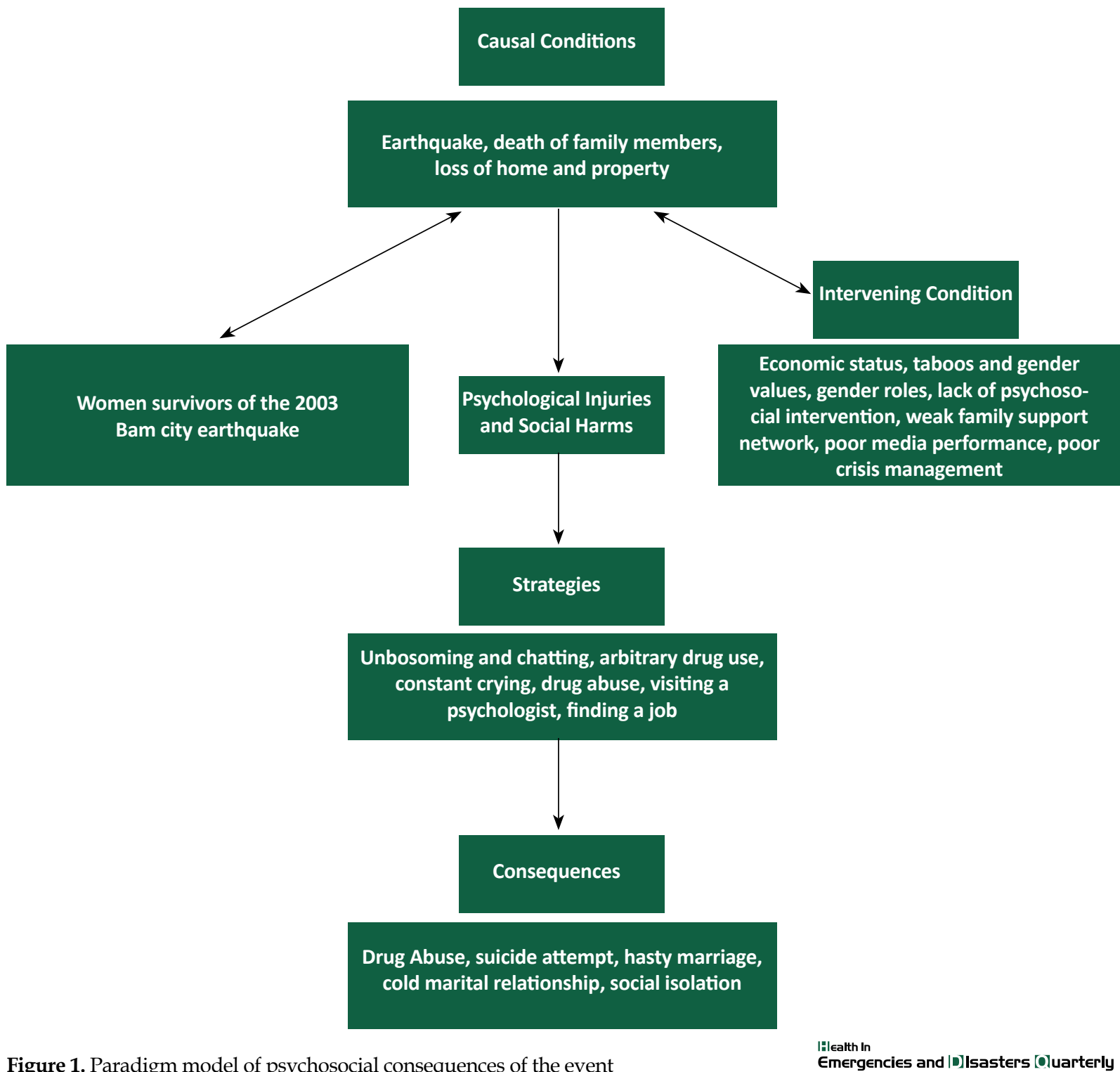

Figure 1. Paradigm model of psychosocial consequences of the event 
Table 1. Index for determining the group of the lower and middle economic classes of the study participants

\begin{tabular}{cc}
\hline Middle Economic Class & Lower Economic Class \\
\hline Has a balanced number of capital types & Has a small number of capital types \\
Having a job and income & Unemployment and no income \\
Private residential house & Rental house or condominium \\
Desirable residential areas (Azadi, Amirkabir, Nashdamtari, Moal- & Unfavorable residential area (Black House, Hafez Abad, Seyed \\
lem Boulevard, Baghdasht, Qasr Hamid, Mahdab) & Taheruddin, Date Factory, Dashtoieh) \\
\hline
\end{tabular}

cupational status. Consequently, more detailed questions were probed based on the theoretical sampling approach.

To validate the research, being a native researcher of the region and based on life experience and using reliable methods, he was able to identify the lower and middle urban areas of the city. Attempts were made to involve women in both regions in this study; however, for promoting the reliability of the obtained moderate and poor life index, focus groups were conducted by inviting several Bam-resident women. For example, one of the questions probed the group's opinion on the average and poor conditions in Bam. In response, the study participants noted the following:

- Owning or not a house

- Owning or not a car

- Owning or not a palm tree

- Living in marginalized regions, like near the old citadel

- Employment in government agencies (Table 1).

Yaghfori, Rousta, and Kouhshahiarticle (2016) studied the neighborhoods of Bam City for a long time after the earthquake. They divided the neighborhoods based on the quality of life and economic indicators [11]. This study helped the researcher to classify the neighborhoods based on after and before the earthquake. They have divided Bam City concerning the social dimension of quality of life into the following, respectively:

1. Undesirable socioeconomic neighborhoods, including Siah Khaneh, Hafezabad Seyed Taheruddin, Date Factory, Dashtoieh, Sangestan, and Espikan.

2. Favorable social and economic middle neighborhoods: Azadi, Amirkabir, Nashdamtari, Moallem Boulevard, Baghdasht, Qasr Hamid, and Mahdab.
Furthermore, the preliminary interviews conducted with the informants of Bam City Health Center determined that the neighborhoods of Spikan and Seyed Taheruddin included the highest number of poor class families; therefore, the group of lower economic class women from Spikan neighborhood, and Seyed Taheruddin and middle-class women from other areas of Bam City were selected. However, both groups were allowed to begin their narratives with the experiences of the first minutes and days of the earthquake in a narrative interview (i.e., freely and away from the confines of research questions). This division has eventually led to discovering newer and more fundamental concepts and avoiding the repetition of questions. Although it became more difficult for a qualitative researcher at first, we could better interview individuals and discover new data. Besides, after interviewing 11 low-class women and 16 middle-class women, data saturation was established (Table 2).

After conducting each interview based on the grounded theory method, for each narrative, data analysis was performed in 3 stages, as follows: open coding, axial coding, and selective coding. In these stages, the interviews were conducted line by line, analyzed, and coded based on the characteristics and dimensions of each concept of open and raw codes. Then, in the axial coding stage, any number of codes that were related respecting concept and characteristics were collected and classified; thus, after breaking the interviews into codes and subcategories in open coding, in this step, they were related and categorized on the main topics. Moreover, selective coding was followed by selecting concepts and topics, i.e., effective in extracting the central theme of the research.

This step was conducted to integrate and refine the data to emerge the primary category (Strauss \& Corbin, 1998) [12]. Accordingly, the interviews were first coded line by line, and after the emergence of the initial categories, sentences and paragraphs were coded in line-by-line coding. Subsequently, 458 raw data were obtained from interviews with women in the lower economic group; 577 raw data were obtained from interviews with women in the middle 
Table 2 . The characteristics of the study participants

\begin{tabular}{|c|c|c|}
\hline \multirow[t]{2}{*}{ Characteristic } & \multicolumn{2}{|c|}{ Multivariate } \\
\hline & $24-30$ & 3 \\
\hline \multirow{6}{*}{ Age, $y$} & $31-37$ & 12 \\
\hline & $38-44$ & 8 \\
\hline & & \\
\hline & $45-51$ & - \\
\hline & $52-58$ & 2 \\
\hline & $59-66$ & 2 \\
\hline \multirow{5}{*}{ Educational status } & High school & 6 \\
\hline & Diploma and above & 14 \\
\hline & & \\
\hline & BA & 5 \\
\hline & MA and above & 2 \\
\hline \multirow{3}{*}{ Occupational status } & Employed & 18 \\
\hline & & \\
\hline & Unemployed & 9 \\
\hline \multirow{3}{*}{ Marital status } & Single without marriage & 3 \\
\hline & Married & 20 \\
\hline & Unmarried (divorce-death) & 4 \\
\hline Respondents & & \\
\hline
\end{tabular}

economic group, and 1035 raw data were obtained in total. Moreover, raw data were organized per concept, using the 3 methods of question design, comparison, and frequent reference to data. The number of concepts created in this stage was 929 items for the lower group, 1675 concepts for the middle group, and 2604 concepts for both groups (Table 3).

\section{Results}

This article examined the causal effects, intervening conditions in developing psychosocial consequences after the disaster, and women's strategies to cope with those and their consequences in their personal and social lives. Moreover, due to the repetition of this concept during the responses and the experience of psychological problems in the concepts and categories derived from the research, this phenomenon was selected as the main category. Selecting this phenomenon had other reasons, including the ability to attract other categories related to the mental health status of women survivors of the Bam earthquake.
Finally, after reconstructing the narratives, comparing the concepts with each other, and referring to the theoretical notes based on the paradigm model of Strauss and Corbin (1998), axial coding and a logical and orderly process between the categories were created. Accordingly, causal conditions and intervening conditions of the phenomenon of psychosocial consequences and strategies of women involved in this phenomenon and the consequences of this phenomenon and strategies on women's personal and social lives have been extracted from the obtained data.

\section{Causal conditions}

"Causal conditions are sets of events or incidents that create issues and problems related to a phenomenon; they specifically explain why and how individuals or groups react to the phenomenon in certain manners. The circumstances we find ourselves in it in personal motivations or biographies may be derived from time, place, culture, laws, regulations, beliefs, economics, power, or gender characteristics, as well as the social interactions, organizations, and institutions (or all); "these issues are a potential source of circumstances" (Strauss \& Corbin 1998). Exposure to earthquakes, regard- 
Table 3. Examples of the initial coding of raw data concepts of psychosocial harm

\begin{tabular}{|c|c|c|}
\hline Main category & Subcategory & Concepts \\
\hline $\begin{array}{l}\text { Psychosocial } \\
\text { consequences }\end{array}$ & $\begin{array}{l}\text { Feeling guilty } \\
\text { Feeling lonely } \\
\text { Isolationism }\end{array}$ & $\begin{array}{l}\text { Nervousness, isolation, incomplete grief, long-term mourning, constant crying, inability to } \\
\text { make proper decisions, psychosomatic problems, sadness at the death scene of loved ones, } \\
\text { feeling lonely, feeling homeless, not accepting the death of a family member, feeling help- } \\
\text { less to save the family, suffering, feelings of guilt for survival, wrong decision to choose a } \\
\text { spouse, self-punishment, despair, the lack of understanding of problems, inability to solve } \\
\text { problems, inability to reject drug compliments, feelings of anger, suicide attempts, nervous } \\
\text { breakdown, isolation request, not forgetting the death of loved ones and grief recurrence, } \\
\text { chronic depression, depression caused by earthquakes, inability to make proper decisions } \\
\text { due to fear and depression, psychosomatic problems, not attending family weddings, the } \\
\text { lack of research on the status of the suitor, self-punishment, inability to solve problems with } \\
\text { spouse, feelings of anger towards others, pessimism, social isolation, withdrawal getting out } \\
\text { of bed, feeling hopeless, losing faith in the future, wishing for death, not paying attention to } \\
\text { psychological and emotional needs, losing hope in life, psychological shock from observing } \\
\text { debris, severe psychological shock from hearing the news of family members' death, the } \\
\text { lack of forgetting painful scenes, lowering the spirit of cheerfulness, the lack of life expec- } \\
\text { tancy, wishing to die, lack of rational thinking, feeling angry, rage, resentfulness, hatred of } \\
\text { emergency care workers, impulsive behaviors }\end{array}$ \\
\hline
\end{tabular}

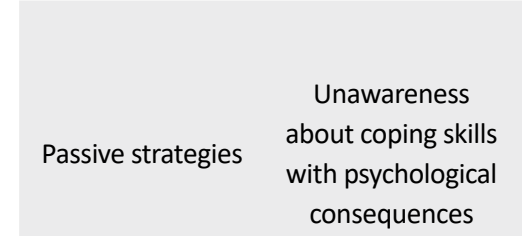

Underlying Socio-cultural

conditions barriers
The lack of follow-up of psychological services, the arbitrary discontinuation of psychiatric drugs, feelings of pleasure from drug use, psychological distress caused by the death of loved ones, denial of drug use, the lack of awareness of ways to reduce pain, crying, taking nerve pills, the arbitrary discontinuation of drugs, the lack of communication skills, punishment for making the wrong choice, not making the right decision, not being able to cope with the problems of living alone, feeling helpless, not understanding the problems correctly, projecting

Low education, cultural poverty, the lack of education in temporary housing, the cultural and social situation of the pre-earthquake area, the lack of learning life skills, unemployment, substance dependence in a family member
Coping strategies Rational strategic actions
Learning to sew, working in a clothing workshop, baking bread, raising chickens, embroidering leather, heartbreaking with friends, talking to a consultant

\section{Hilealth in}

Emergencies and |D]isasters [O]uarterly

less of gender, is associated with psychological distress, especially Post-Traumatic Stress Disorder (PTSD). Earthquake-related psychological symptoms can be short-term or long-term. In Bam City, numerous survivors still present poor mental health, including depression and despair.

Nazanin is single and an employee. She has higher education. She declared: "everything goes back to the morning of the earthquake, and from that year, I have anxiety and depression, concerns about the future as well as housing.

Nava lost her father, mother, and 3 brothers during the earthquake. She described the mental state of that time and today, as follows: "in the first days, I wished I had died with them. My depression is getting worse and worse! I still feel depressed.

In the meantime, those women who lost their parents and family members presented more profound psychological experiences and experienced depression more than others. Some manifested suicidal ideation and attempts. Moreover, the earthquake caused economic insecurity due to the destruction of property and temporary economic dependence of the surviving family, and some of these individuals lost their suitors, which caused further issues.

\section{Background}

The background represents a set of specific conditions within which action/reaction strategies are performed. Background indicates the location of events related to the phenomenon along with a dimensional range [13]. The background of this study was the life experiences of women rescued from the devastating earthquake of December 26, 2003, in Bam City and living in emergency tents and private shelters or camps. 
Interfering conditions Strauss and Corbin (1998) argued that "intervening conditions are those that reduce, increase, or change the effects of causal conditions on phenomena". For example, a teenager who, despite the availability of drugs, suddenly feels that drug use is not suitable for them, while the intervening situation can explain why some teenagers try drugs and others do not, both causal and intervening conditions arise at the macro or micro level, and strategies/interactions always follow a set of these conditions [12]. In this study, we encountered a network of gender, economic, social, and cultural interfering causes, including the following:

Economic class Poverty, physical harm, fear of starvation for self and family were important factors in the lower economic class. Thus, it is necessary to further analyze the economic class. The complex interaction of gender and economic class has imposed further complications on the research participants who reported no desirable economic status before or during the earthquake. However, no appropriate measures have been conducted in this regard.

Gender-Wise violence: The category of gender-wise violence included the subcategories of domestic violence experience, gender-related taboo, and the harassment of women by men and society, making women more vulnerable to psychosocial harm in times of disaster. Accordingly, such experiences impose further stress on them. Thus, they are afraid of participating in social activities outside the tent or the shelter. Eventually, they become more isolated and depressed.

Poor family and kinship support network The next intervening factor was the lack of support from family members and relatives. In this study, it was referred to the category of family and social support network. The study participants in this category reported positive and active intervention of parents, husbands, and relatives. Most of the study subjects with psychological trauma and deficiencies in decisionmaking and emotional problems had highly restricted family and social support. Emotional and social support, in which a family member or acquaintance helps another, reduces the effects of stress when faced with difficulties; improves women's vulnerability in society and the family, and promotes their mental health status. These women live different lives from their abandoned counterparts, although some women were more resilient than others.

\section{Gender roles}

Traditionally and culturally, women play the role of caregivers in the family. Playing this role in regular times for women has become a behavioral habit, and they have reported no particular problem; however, performing these acquired roles poses specific problems for women. In a di- saster, these roles increase women's stress levels. This is because women are the primary caregivers; they encounter additional anxiety over the disaster, which includes caring for children and family victims.

The lack of regular and continuous psychological interventions

Regular counseling and psychotherapy interventions are necessary for all individuals at risk of a crisis caused by accidents. Research revealed that the shorter the time to providing medical care to the injured, the more significant the impact. Moreover, it enhances the odds of appropriate interventions in a crisis to prevent the immediate or longterm symptoms of mental disorders. Besides, proper interventions lead to personal prosperity growth.

Multiple interviewees commented on the poor state of psychological interventions or the absence of a psychologist in the days following the earthquake. The presence of foreign or non-native psychologists increased the knowledge of Iranian psychiatrists and the experiences of foreigners in this field; however, a relevant disadvantage was signified by the research participants as it is challenging to communicate with them. This is because they did not understand their language. Incomplete prescription and the non-follow-up of neuroleptics and sedatives were also among the problems that exposed the survivors to severe shock; consequently, they consumed medications due if having suicidal ideation or self-medicated or stopped adherence to pharmacotherapy arbitrarily. Furthermore, the lack of follow-up and psychotherapy provision to the patients under psychiatric supervision caused them to manifest withdrawal symptoms due to the arbitrary discontinuation of drugs. Sometimes, they consumed drugs to manage biopsychological pain.

Additionally, the duration of psychological interventions in Bam was concise and limited to the early months or the deployment of psychologists in a specific area and specific to the camps. Another problem with psychological interventions is the lack of expertise of the troops sent to the region and unfamiliarity with the culture of the area; thus, the survivors did not approve the prescription suggestions; survivors' trust in psychologists also played a critical role in this regard.

Poor crisis management of the emergence care workers and the media

The inappropriate behavior of the healthcare staff or assisting visitors to Bam was among the latent reasons that the residents of Bam, especially women, were emotionally harassed. They were secretly concerned about the end of 
that period. Why should we, who had everything, encounter these behaviors? Some individuals who visited Bam to gain experience and help did not properly treat the survivors. Also, due to ignorance and to help, they attempted to bury the dead under the rubble without informing their families.

\section{Phenomenon}

Strauss and Corbin, the creators of this theoretical paradigm model in qualitative research, believed that the phenomenon is "a term that answers the following question: What is going on here?" In the search for phenomena, we searched the repetitive patterns of events, happenings, or actions/interactions that represent individuals' words or actions, alone or with others, in response to problems and situations. Besides, each pattern has its set of conditions to which it relates.

Based on the obtained data and ranking of subcategories per comprehensiveness and repetition in the narrations, this category was selected as a core class. This concept was selected from the perceived meanings of the research, in consultation with 3 experts in psychology, psychiatry, and social work. Furthermore, it includes almost all the feelings and psychological and emotional experiences of female narrators' categories, such as PTSD, depression, inability to make decisions, decreased logical perception, isolation, constant crying, anger, loneliness, suicidal ideation and attempt, the lack of desire for life, and the lack of hope for the future; this phenomenon was common in both study groups who, to some extent, have experienced it and its consequences.

\section{Actions and interactions}

Everyday routine strategies, i.e., how individuals cope with the situations and issues they face. These data indicate what individuals or organizations, the social world, or nations say or do strategic actions/interactions are purposeful and intentional, i.e., used to solve a problem. Thus, they accordingly shape the phenomenon. Procedures and actions/ interactions are approaches to respond to events in daily life and organizations, including rules, regulations, and procedures. The term action/interaction is an essential concept. This is because individuals dedicate definition or meaning to the situation [12].

$$
\text { - to cry }
$$

- Visiting the cemetery

- The arbitrary use of drugs

- Referring to psychiatrists and psychologists in the area
- The acceptance of drug use compliments by relatives

- Work and activity

\section{Consequences}

Following the consequences is important in fundamental theory [13]. The last part of the Strauss-Corbin paradigm model consists of the term consequences, the result of the phenomenon, and the strategies chosen in the lives of actors. It should be noted that not all actors will necessarily experience these consequences, i.e., also due to individual and social differences. Consequences, like conditions, have intrinsic properties, e.g., consequences may be singular (usually not) or categorical.

They may be visible to the individual, but not to others, or vice versa. They may be immediate or cumulative, reversible, or unpredictable. Their impact may be limited (affecting only a small part of the context) or more widespread (a sequence of unfortunate events that completely alters a context); we, as analysts, need to consider most of these consequences in our analysis [12]. An additional point to this consequence can be the phenomenon of another paradigm model that must separately examine the causal and intervening conditions. An example includes suicide attempts in women in natural disasters, i.e., a consequence of the phenomenon of cognitive-emotional trauma of actors in natural disasters. The main reason for such attempts is depression and PTSD. However, it can be studied as a pattern of behavior in times of natural disasters in both genders.

The consequences of psychosocial trauma on the personal and social lives of female survivors of the Bam earthquake are beyond the scope of this study; however, based on the obtained data and the coping strategies fostered by the research participants in response to their mental problems included the following:

\section{Drug use}

Several individuals at risk of psychological consequences have used substance abuse as a coping mechanism. With the suggestion of relatives and family members, they accepted substances due to alleviate fatigue, the pain caused by the death of loved ones, physical pains, and other mental health issues. These are emotions that those at risk of mental illness may experience. Still, the availability of drugs, the presence of a family member with substance dependence, the compliments of those around them, and the arbitrary use of sedatives are the distinct boundaries of their choice. 
Additionally, the interviewed substance-dependent women stated the incomplete use of prescribed psychiatric drugs. They consumed such drugs and gave them up due to drowsiness and poor mobility. Moreover, local psychologists and psychiatrists did not follow their treatment, while these women arbitrarily took sedatives.

\section{Suicide}

Suicide is an important problem in the general health of survivors of natural disasters, i.e., directly related to survivors' mental state and emotional, cognitive traumas.

Raheleh explained the following: I watched all the videos of the corpses on my cousin's camera (reminding me of the scene of the death of a loved one). Then, I took the pills and went (the availability of the pills) to a carefree world, I took the razor (availability of suicide tools) and hit the vein, then I committed suicide several more times (repeated suicide attempts) with both pills and razors (re-availability of pills). After several more attempts, my physician did not prescribe me pills. They took me to the hospital, and I took my pills there and got back to the barracks.

"I was so humiliated and sad that I committed suicide, I took several pills that I do not know what they are," mentioned Naghmeh, who still has a feeling of disgust with the earthquake and Bam City and some of Bam City residents.

Nazanin declared: "It was 10 days after the earthquake that I committed suicide. The reason was the feeling of despair I encountered during the earthquake. This is because I thought we would never be able to stand up on our feet again and would we have a house in a few years".

\section{Sexual dysfunctions}

In unfortunate events, such as natural disasters or famine and starvation, sexual need and desire may be affected; therefore, it might decrease or increase in this case, which affects both genders. In this study, the research participants cited the most substantial reason for the decrease in sexual desire as depression for themselves and their husbands due to mourning the death of loved ones. Besides, some considered such relationships inappropriate and felt guilty because of the death of those around them; some were reluctant to do so for the fear of being naked during the aftershocks. Additionally, living in groups in tents and barracks and the lack of private bathrooms caused shame and embarrassment in women. This issue suppressed this need in both genders, which affected the emotional feelings and couples' relationships.

\section{Isolationism}

Isolation is a consequence of psycho-cognitive trauma and a consequence of improper treatment. The subject becomes angry because of what happened, asking why me? As a result, they consider themselves separate and alien from others. They defend themselves against others. They assume others do not understand their pain. This issue causes the individual to neglect personal affairs and life and resort to dreams and imagination. The consequences of isolationism are more pronounced among families with more severe economic problems than those who have encountered the death of their loved ones.

\section{Discussion}

In the aftermath of a natural disaster, like an earthquake, in addition to physical and economic harms, women experience mental health problems, domestic violence, unemployment, increased poverty, substance dependence, suicidal ideation, low self-esteem, migration, and sometimes polygamy.

The current study data indicated that with the occurrence of the disaster, psychological phenomena outside the network of socioeconomic reasons are examined and only presented in medication. In the Bam earthquake, psychological interventions focused on psychiatric and temporary sedation treatments. After two years of parallel work between different organs, the social support system has discontinued without proper functioning in Bam City. The psychosocial health of the survivors, especially vulnerable groups, has not been followed up while this phenomenon will not be wholly cured without psychosocial intervention.

Domestic research indicated that such psychological consequences in the vulnerable group of women are not limited to the natural risk of earthquakes. For example, Seyedin et al. (2017) explored PTSD in the two flood-hit cities of Neka and Behshahr. Accordingly, they found that stress significantly increased in divorced and widowed women [14].

Our research revealed that surviving women in both groups, who experienced the deaths of their parents, children, and loved ones, presented suicidal ideation, and sometimes, even committed suicide. Bani Asadi et al. (2019), in another study conducted in Bam City, concluded that women were more likely than men to suspect mental disorders $(49.93 \%$ of men vs. $54.27 \%$ of women); the prevalence of mental disorders increases with the loss of close relatives and age. Moreover, widows and divorced women $(66.66 \%)$, illiterate and dropouts $(57.48 \%)$, and the elderly $(77.12 \%)$ had the highest average values in terms of mental disorders [15]. 
In addition to vulnerable women, our study found that middle-class women were exposed to psychosocial consequences by losing property, being forced to live in others' homes, and lacking emotional support.

In a qualitative study on the psychosocial health status of surviving women in Bam City, we found a very short interval between suicidal ideation and suicide attempt; however, despite symptoms, like despair, suicidal ideation increased the use of sedatives, isolation, prolonged crying, and so on. Physicians and family did not present professional attention. Despite the experience of suicide attempts, sedatives and razors have been available to this population.

All studies highlighted the importance of psychological preventive measures in the crisis among mourning individuals. Subjects are more resilient due to the presence of others, family, and friendly support; however, in mass mourning, due to the death of natural disasters, social structures and family roles are damaged, and the human psyche encounters severe shock, astonishment, anger, sorrow, and depression. Therefore, given the effects of natural disaster-related mental illness can last for years, comprehensive screening programs are required at regular intervals to ensure mental health recovery after a disaster. Psychological interventions should be implemented among the residents of the region for a long time.

One of the major limitations of our study (i.e., conducted 14 years after the Bam earthquake) was restricted access to the survived women and residents and their interest in recalling the memories of that time. The passing of time causes the forgetfulness of the details of life and psychological events of that time. Moreover, due to the reliance and emphasis on the qualitative study of grounded theory on field interviews and in-depth continuous travel and residence in Bam City also faced difficulties. Additionally, due to the confidentiality of the statistics of female-headed households or addicted women and the lack of cooperation of some responsible institutions, researchers could not benefit from official statistics and documents in this regard.

\section{Conclusion}

The current research data suggested that some women in Bam City, due to illiteracy, ignorance, poverty, as well as family and cultural conditions, to reduce psychological consequences have adopted strategies that have caused adverse consequences, such as substance dependence, divorce, and psychosocial issues related to the socio-cultural conditions of the region. After more than 17 years since the Bam earthquake, it has also affected the citizens of Bam City, Ahar, Varzeqan, and Kermanshah. The following statements were extracted by the data analysis and comparison of paradigm models:

The lack of psychosocial intervention, the lack of family support, and increased socioeconomic capital of women, and the implementation of emotional and irrational strategies of psychosocial consequences have been the main characteristics of the study subjects in experiencing negative consequences.

- The severity of psychosocial consequences in women in Bam City was different in the two groups of middle and lower economic classes.

The destruction of the house and the death of family members have affected women's emotional and cognitive conditions in Bam City.

- Family support is among the essential factors in choosing a rational strategy and recovery for women in Bam City.

- There was a relationship between emotional-cognitive trauma in women and the tendency to use drugs in women in Bam City.

- Lower-Class women chose more irrational strategies to cope with emotional-cognitive trauma, compared to their middle-class counterparts.

- There was a relationship between employed women and homemakers in Bam City during the earthquake and increasing women's psychosocial health.

Finally, we believe that women in Bam City, due to the direct and indirect effects of the earthquake and the intervention of economic status and family social capital, have chosen and implemented different strategies against psychosocial consequences caused by the Bam City earthquake. These strategies provided significant effects on their psychosocial recovery and reconstruction.

\section{Suggestions}

- The cooperation of a team of psychologists, psychiatrists, and social workers in examining the situation of women in the region.

- Training the expertise of crisis intervention teams and training social workers as social workers and psychologists.

Visiting low-income families, identifying their needs, and meeting their fundamental biological and economic needs by a social worker. 
- Holding group therapy sessions for women in times of disaster by experienced psychologists.

-The lack of focus on pharmacotherapy in the treatment of psychological shock and post-catastrophic depression.

- Investigating and following up the mental conditions of women referring to treatment teams and archiving observations and treatments.

\section{Ethical Considerations}

\section{Compliance with ethical guidelines}

In this study, before starting work, obtaining informed consent of the participating women was done. Also, permission was obtained to record the voice and write the narrations. In addition, the characteristics of the researcher and the purpose of the research were presented to them in plain language. They were assured that their real names would not be used in the research.

\section{Funding}

This research did not receive any grant from funding agencies in the public, commercial, or non-profit sectors.

\section{Authors' contributions}

All authors equally contributed to preparing this article.

\section{Conflict of interest}

The authors declared no conflict of interest.

\section{References}

[1] Kamkar, M. [Gender and health in disaster (Persian)]. Social Welfare Quarterly. 2003; 3(11):288-79. https://refahj.uswr.ac.ir/ article-1-2414-fa.html

[2] Enarson E, Fordham M. Lines that divide, ties that bind: race, class, and gender in women's flood recovery in the US and UK. Australian Journal of Emergency Management. 2000; 15(4):43-53. https://www.researchgate.net/publication/289759177_Lines_ that_divide_ties_that_bind_Race_class_and_gender_in_women's_flood_recovery_in_the_US_and_UK

[3] Loghmani S. [Women and crisis (Persian)]. Tehran: Shiraze; 2014. http://opac.nlai.ir/opac-prod/bibliographic/3445693

[4] Titchener JL, Kapp FT. Disaster at buffalo creek. Family and character change at buffalo creek. The American Journal of Psychiatry. 1976; 133(3):295-9. [DOI:10.1176/ajp.133.3.295.][PMID]

[5] Livanou M, Kasvikis Y ,Başoğlua M, Mytskidoub P, Sotiropouloub V, Spanea E, et al. Earthquake-related psychological distress and associated factors 4 years after the Parnitha earthquake in Greece. European Psychiatry. 2005; 20(2):137-44. [DOI:10.1016/j. eurpsy.2004.06.025]
[6] Kõlves K, Kõlves KE, De Leo D. Natural disasters and suicidal behaviors: A systematic literature review. Journal of Affective Disorders. 2013; 146(1):1-14. [PMID]

[7] Parkinson D, Duncan A, Archer F. Barriers and enablers to women in fire and emergency leadership roles. Gender in Management. 2019; 34(1):78-93. [DOI:10.1108/GM-07-2017-0090]

[8] Strauss AL, Corbin JM. Basics of qualitative research methods [B. Mohammadi, Persian trans.]. $3^{\text {rd }}$ Ed. Tehran: Institute for Humanities and Cultural Studies; 2011. http://opac.nlai.ir/opac-prod/ bibliographic/766135

[9] Echonrich J, McGead Sh. Psychological first aid and support in disasters. [H. Nasiri, R. Samoei, J. Forouzandeh, Persian trans]. Tehran: Helel Ahmar, 2010. https://fidibo.com/book/

[10] Zahedi Asl M. [Participation of the earthquake victims in rebuilding the damaged regions (Persian)] .Journal of Social Sciences. 2000; 7(11-12):145-75. https://qjss.atu.ac.ir/article_5191. html?lang=en

[11] Yaghfoori H, Rusta M R, kooshaahi M. [Spatial evaluation of quality of life indicators in the neighborhoods of bam city after earthquake by using multi-criteria decision-making models (Persian)]. Social Welfare Quarterly. 2016; 16(61):187-220. http://refahj.uswr.ac.ir/article-1-2571-en.html

[12] Strauss A, Corbin JM. Basics of qualitative research: Techniques and procedures for developing grounded theory. New York: Sage 1998. https:// books.google.com/books?id=y561swEACAAJ\&dq

[13] Azkia M, Imani Jajarmi H, Farzizadeh Miandehi Z. [Applied research methods, application of basic theory (Persian)]. Tehran: Keyhan, 2011. https://www.adinehbook.com/gp/product/9644582745

[14] Seyedin H, HabibiSaravi R, Sayfouri N, Hoseini Djenab V, Ghasemi Hamedani F. Psychological sequels of flood on residents of southeast Caspian region. Natural Hazards. 2017; 88(Suppl 1):96575. [DOI:10.1007/s11069-017-2926-z]

[15] Baniasadi M, Divsalar P, Noorbala AA, Eslami Shahrbabaki M, Aflatoonian B, Ashrafi Asgarabad A. Bam earthquake survivors' mental health status 12 years after the earthquake: a populationbased study. Archives of Iranian Medicine. 2019; 22(2):59-64. [PMID] 